\title{
Is Individual Educational Level Related to End-of-Life Care Use? Results from a Nationwide Retrospective Cohort Study in Belgium
}

\author{
Nathalie Bossuyt, M.D.,' Lieve Van den Block, Ph.D., ${ }^{2,3}$ Joachim Cohen, Ph.D., ${ }^{2}$ Koen Meeussen, Ph.D., ${ }^{2}$ \\ Johan Bilsen, Ph.D., ${ }^{2}$ Michael Echteld, Ph.D., ${ }^{4}$ Luc Deliens, Ph.D., ${ }^{2,5}$ and Viviane Van Casteren, M.D.'
}

\begin{abstract}
Background: Educational level has repeatedly been identified as an important determinant of access to health care, but little is known about its influence on end-of-life care use.

Objectives: To examine the relationship between individual educational attainment and end-of-life care use and to assess the importance of individual educational attainment in explaining differential end-of-life care use.

Research Design: A retrospective cohort study via a nationwide sentinel network of general practitioners (GPs; SENTI-MELC Study) provided data on end-of-life care utilization. Multilevel analysis was used to model the association between educational level and health care use, adjusting for individual and contextual confounders based upon Andersen's behavioral model of health services use.

Subjects: A Belgian nationwide representative sample of people who died not suddenly in 2005-2007.

Results: In comparison to their less educated counterparts, higher educated people equally often had a palliative treatment goal but more often used multidisciplinary palliative care services (odds ratios [OR] for lower secondary education 1.28 [1.04-1.59] and for higher [secondary] education: 1.31 [1.02-1.68]), moved between care settings more frequently (OR: 1.68 [1.13-2.48] for lower secondary education and 1.51 [0.93-2.48] for higher [secondary] education) and had more contacts with the GP in the final 3 months of life.

Conclusions: Less well-educated people appear to be disadvantaged in terms of access to specialist palliative care services, and GP contacts at the end of life, suggesting a need for empowerment of less well-educated terminally ill people regarding specialist palliative and general end-of-life care use.
\end{abstract}

\section{Introduction}

$\mathbf{T}$ HE PRINCIPLE OF EQUITABLE DISTRIBUTION of health care and the commitment not only to pursuing the efficient delivery of high-quality medical care but also to ensuring equitable access to that care is widely acknowledged in individual countries, by international organizations such as OECD and supranational institutions such as the European Union. ${ }^{1-3}$ Equitable access is often defined as horizontal equity ("people in equal need are treated equally") and, since access in itself is hard to measure, it is frequently conceptualized as need-adjusted health care use. ${ }^{4}$ Differential health care use can be due to differences in the patient's health care seeking behavior and/or differential treatment by the health care system. Both mechanisms are potentially influenced by the patient's educational attainment, partly via its mediator "health literacy" (defined as "the degree to which individuals have the capacity to obtain, process and understand basic health information and services needed to make appropriate health decisions" $)^{5-11}$

End-of-life care can be considered as a combination of general health care and (specialist) multidisciplinary palliative care, the latter skilled and experienced in specific aspects of health problems at the end of the life. Although socioeconomic inequalities in access to end-of-life care have been studied before, most studies have a limited scope (e.g., specific patient diagnosis group, small geographical areas), resulting in equivocal findings. ${ }^{12-20}$ Differential end-of-life care use according to

\footnotetext{
${ }^{1}$ Scientific Institute of Public Health, Operational Directorate Public Health \& Surveillance, Brussels, Belgium.

${ }^{2}$ End-of-Life Care Research Group, ${ }^{3}$ Department of General Practice, Vrije Universiteit Brussel, Brussels, Belgium.

${ }^{4}$ EMGO Institute for Health and Care Research, ${ }^{5}$ Department of Public and Occupational Health, EMGO Institute for Health and Care Research, VU University Medical Centre, Amsterdam, The Netherlands.

Accepted May 24, 2011.
} 
educational attainment in particular has hardly been studied until now.

In Belgium, the conditions for equitable access in end-oflife care are theoretically in place since Belgian health policy has provided a legal, financial and structural basis to avoid differential end-of-life care use. The Law on Palliative Care (2002), the Law on Patients' Rights (2002), and the laws regarding the right to take palliative care leave stress the importance of equal access, entitle every patient to benefit from palliative care, enable the vast majority of the population to take leave from work to care for a terminally ill relative and provide the palliative care facilities with structural funding. ${ }^{21,22}$ Financial benefits help cover the costs of palliative medication, materials for comfort care, general comfort aid, and fees in primary care that are not covered by the compulsory health insurance, and visits of multidisciplinary palliative home care teams are free of charge for the patient. The division of the country into palliative care regions with palliative networks coordinating the multidisciplinary palliative care service at regional level, ensures the presence of at least one palliative home care support team as well as a few (mostly in-hospital) palliative care units at close proximity to the patient's residence. Moreover all Belgian hospitals and most rest and nursing homes have a palliative support team at their disposal. $^{23}$

However, the question remains to what extent this egalitarian policy results in actual equitable use of end-of-life care, i.e., whether people with low health literacy/educational attainment are restricted in their use of end-of-life care or are treated differently by the health care system. Therefore, this article tackles the research question whether there is a link between individual educational attainment and end-of-life care use. The hypothesis or expectation is that, given the egalitarian policy, lower educated people have the same palliative treatment goal and the same frequency of multidisciplinary palliative care services use, of transitions between end-of-life care settings and of primary care contacts as higher educated people. Andersen's behavioral model of health services use is hereby used as a conceptual framework for the study of equitable access.

\section{Methods}

\section{Design}

The SENTI-MELC study, a nationwide retrospective cohort study, gathers patient-based information on end-of-life care via the national Belgian Sentinel Network of General Practitioners, resulting in a sample clustered by general practioners (GPs) ${ }^{24-27}$

\section{Data}

The network consists of GPs who register weekly, using standardized registration forms, data on selected health problems. The GPs are representative for all Belgian GPs in terms of age, gender, and geographical distribution. The study referral population is the total Belgian population and, based on their annual number of patient contacts, the GPs participating in the network are estimated to cover 1.5\% (or 150,000 inhabitants) of that total Belgian population. ${ }^{28}$

\section{Subjects}

From January 1, 2005 until December 31, 2007, the GPs registered the death of every patient, aged 1 year or older, within their practice. Both deaths certified by the GPs and deaths about which they were informed of afterwards were included. To prevent recall bias the physicians were instructed to register immediately after being informed of the patient's death. GPs used their patient records and all information they received from other medical services and physicians to complete the registration forms. In this study only data from people who, according to the GP, did not die "suddenly and totally unexpectedly" were taken into account, in order to focus on patients who were theoretically able to receive terminal care.

\section{Measures}

The registration form collected among others, information on sociodemographic data, general treatment goal and specific treatments, use of multidisciplinary palliative care services, transitions between end-of-life care settings, and caregivers involved. All data referred to the last 3 months of the patient's life.

In this study, educational level was categorized into (1) primary or lower, (2) lower secondary, and (3) higher secondary/higher education. Although based on socioeconomic characteristics of the individual patients and thus more valid than the majority of research studies at general practice or primary care provider level that use ecological deprivation measures because of financial and ethical constraints of accessing individual socioeconomic data, ${ }^{29}$ the educational level was only assessed by the GP and may therefore lack validity.

End-of-life-care was operationalized in four ways: (1) having a palliative treatment goal, (2) use of multidisciplinary palliative care services, (3) number of care setting transitions, and (4) frequency of patient-GP contacts. For the first two outcomes, only data for 2005 and 2006 were available and for the latter two data for 2005-2007.

The main treatment goal as judged by the GP was measured at three periods of time (months 2 and 3 prior to death, weeks 2-4 prior to death and the last week of life) via the generic question, "What was the main goal of this patient's treatment?" (answering categories: "cure," "prolonging life," and "comfort/palliation"). In this study, all patients for whom the category "comfort/palliation" was checked at least once were considered having had a palliative treatment goal at some point during the last 3 months of their life.

All patients who at some point in the final 3 months used a multidisciplinary palliative home care team, a palliative support team in a care home or in a hospital, or resided in an inpatient palliative care unit or visited a palliative day care center were considered to have used multidisciplinary palliative care services

Each relocation between care settings (home, rest and nursing home, hospital and inpatient palliative care unit) was counted as a care setting transition. A total number of transitions in the final 3 months of life exceeding 2 was considered to be high.

The number of GP contacts in the final 3 months included both home (or hospital) visits and consultations.

\section{Conceptual model}

Andersen's behavioral model of health services use provides a conceptual framework to study equitable access. The model is based on the idea that understanding health services 
use is best accomplished by focusing on contextual and individual determinants and process of care, and encompasses predisposing, enabling and need factors at both individual and contextual level. Andersen defines equitable access to health services as "...occurring when predisposing demographic and need variables account for most of the variance in utilization, whereas inequitable access occurs when social structure, health beliefs, and enabling resources determine who gets medical care..." 30

In line with Andersen's model, the association between end-of-life care use and educational level was further adjusted for individual and GP-related variables. Independent variables at the individual level included predisposing demographic (age, gender) and social variables (living at home/ care home, living alone); enabling factors (the GP's estimation of the financial status), and need factors (the underlying cause of death serves as a proxy for diagnosis and medical need and the place of death was considered to be a proxy for need of GP contacts in the final days). At the contextual level, there was adjustment for the predisposing demographic factor 'region', the enabling factor "urbanization level" and for characteristics of the GP (age, gender, region or language, size of the practice, solo/group practice and whether there was a trainee in the practice) that can be considered as enabling organizational factors. In 19 practices more than one GP registered cases and there age and gender of the longest participating GP was taken.

\section{Analysis}

The bivariate association between educational level and the binary outcome measures main treatment goal, high number of care setting transitions, and use of multidisciplinary palliative care services was tested by means of a Fisher's exact test (categorical variables with any cell size less than 10 ) or $\chi^{2}$ test (other categorical variables). To test the relationship between educational level and number of GP contacts the KruskalWallis equality-of-populations rank test was used.

For each outcome, a multivariable hierarchical model was fitted, in order to study the association between end-of-life care use and individual educational level, adjusting for both individual and contextual variables and taking into account the clustered sampling design. The binary outcome measures main treatment goal, use of multidisciplinary palliative care services and high number of care setting transitions were analyzed via logistic regression models and the continuous outcome measure intensity of GP contacts was analyzed by means of linear models. Each time, first a generalized estimating equations (GEE) model (taking into account the dependence among patients nested within the same GP and assuming a compound symmetric correlation structure) was fitted in order to obtain odds ratios that are interpretable at the population level.

Statistical data analysis was carried out in SPSS 16.0 (SPSS Inc., Chicago, IL) and STATA 10 (StataCorp, College Station, TX).

\section{Results}

\section{Sample}

In the period 2005-2007, in total 188 GPs provided data on 2445 patients dying not suddenly and in the subsample of
2005-2006 184 GPs registered data on 1690 patients. The basic characteristics of the sample of not suddenly dying patients are shown in Table 1.

\section{Association between end-of-life care use and educational level}

We found no bivariate relationship between the patient's educational level and the main treatment goal in the last three months of life, but people who had at received no more than primary education used multidisciplinary palliative care services less frequently, were less likely to experience more than 2 care setting movements and had fewer GP contacts in the last 3 months of their lives (Table 2).

These results still held when adjusting for individual and contextual variables that also have the potential to influence health care use. Although patients with a different educational level did not have a different treatment goal in the last three months of life, people who had received more than just primary education were 1.3 times more likely to use multidisciplinary palliative care and 1.5 to 1.7 times more likely to move between care settings more than twice. Moreover, not suddenly deceased patients with more than primary education had 1 GP contact more in the last 3 months than less educated people (Table 3 ).

\section{Discussion}

The basic hypothesis of the study was that lower educated people have the same palliative treatment goal and the same frequency of multidisciplinary palliative care services use, of transitions between end-of-life care settings and of primary care contacts as higher educated people. However, notwithstanding the egalitarian health policy regarding end-of-life care in Belgium and in spite of having the same main treatment goal in the final three months of life, lower educated people with a life threatening disease receive multidisciplinary palliative care services less frequently, move between care settings less frequently and have fewer contacts with the general practitioner than better educated people. Since education is a predisposing social variable, certain aspects of end-of-life care use in Belgium are thus not entirely equitable. Moreover, the findings are not quite internally consistent as some outcome measures suggest less educated people are provided with lower quality of end-of life care, but another measure (lower number of health care setting transitions) suggests the opposite.

Treatment goal depends partly on the decision of medical caregivers and the patient's preferences. Although the latter could be related to social structure (other studies showed that patients experiencing financial problems are more likely to prefer comfort care over life-extending care, ${ }^{31}$ or that people with low health literacy are more likely to prefer aggressive treatments at the end of life ${ }^{32}$ ), educational level of the patient did not affect treatment goal here. In comparison with the other three aspects of end-of-life care studied here, treatment goal may be decided relatively more on clinical grounds and less be subject to patient preferences. Moreover, this study looks at treatment goal as evaluated by the GP and therefore may take less into account the actual preferences of the patient.

Notwithstanding the equality in treatment goal, the results of this study in a representative sample of terminally ill patients suggest inequitable use of multidisciplinary palliative care 
Table 1. Characteristics of the Sample of Patients Dying Not Suddenly, Belgium, 2005-2007

\begin{tabular}{ccc}
\hline & \multicolumn{2}{c}{ All deaths } \\
\cline { 2 - 3 } Total number of cases & $\mathrm{N}$ & $\%$ \\
\hline
\end{tabular}

Independent variables

Education level patient

Primary or lower

Lower secondary

Higher secondary/higher education

Missing data

GP's estimation of the patient's

financial status ${ }^{\mathrm{a}}$

Low

Average

High

Missing data

Gender of patient

Female

Male

Age group of patient

$1-64$ yrs

65-84

$85+$

Missing data

950

637

591

267

$267-11$

Place of death

Home

Care home

Hospital

Palliative care unit

Missing data

Usual place of residence patient

Home

Care home or other

Missing data

474

859

331

26

1264

1181

319

1306

790

30

587

642

958

254

4

1640

767

38

Living alone ${ }^{a}$

Alone

With others

Missing data

315

1373

2

Cause of death

Cardiovascular diseases (except stroke)

Malignancies

Respiratory diseases

222

105

171

532

Stroke

Other

Missing data

Level of urbanization of patients'

place of residence

Urban

Rural

Missing data

Region GP

Flanders region

Walloon region

Brussels region

Language GP

French speaking

Dutch speaking

Type of practice

Group practice

Solo practice

Missing data
TAble 1. (Continued)

\begin{tabular}{|c|c|c|}
\hline \multirow[b]{2}{*}{ Total number of cases } & \multicolumn{2}{|c|}{ All deaths } \\
\hline & $\begin{array}{c}\mathrm{N} \\
2445\end{array}$ & $\begin{array}{c}\% \\
100\end{array}$ \\
\hline \multicolumn{3}{|l|}{ Gender of GP } \\
\hline Woman & 479 & 20 \\
\hline Man & 1960 & 80 \\
\hline Missing data & 6 & 0 \\
\hline \multicolumn{3}{|l|}{ Age group of GP } \\
\hline$<40$ yrs & 108 & 4 \\
\hline $40-59$ yrs & 1992 & 81 \\
\hline$>59$ yrs & 339 & 14 \\
\hline Missing data & 6 & 0 \\
\hline \multicolumn{3}{|l|}{ Size of practice } \\
\hline Small (<975 patients) & 802 & 33 \\
\hline Medium ( 975-1425 patients) & 834 & 34 \\
\hline Large (>1425 patients) & 809 & 33 \\
\hline \multicolumn{3}{|l|}{ Trainee in the practice } \\
\hline Yes & 2193 & 90 \\
\hline No & 214 & 9 \\
\hline Missing data & 38 & 2 \\
\hline \multicolumn{3}{|l|}{ Outcome measures } \\
\hline \multicolumn{3}{|l|}{$\begin{array}{l}\text { Main treatment goal in the } \\
\text { final } 3 \text { months }\end{array}$} \\
\hline Curative/life-prolonging & 280 & 17 \\
\hline Palliative & 1365 & 81 \\
\hline Missing data & 45 & 3 \\
\hline
\end{tabular}

Use of multidisciplinary specialist

palliative services in the

final 3 months

No

$1404 \quad 57$

Yes

$951 \quad 39$

Missing data

90

Numbers of care setting transitions in the final 3 months ${ }^{a}$

$<3$ transitions

1508

Missing data

89

Number of GP contacts in the final 3 months

Median (IQR)

$8(5-11)$

${ }^{a}$ Data available for 2005-2006 only

GP, general practioner; IQR, interquartile range.

according to educational attainment. Palliative care use may be better explained by cultural preferences and health beliefs rather than by material circumstances as, among cancer patients, some (but not all ${ }^{13}$ ) Canadian and Italian studies found higher use of palliative care services and referral to palliative home care among more educated persons, ${ }^{14,33}$ whereas oc-

cupational class appears not to be related to access to or utilization of health care, specialist palliative care services, or hospice deaths. ${ }^{12,16-18,20}$ As well as potentially having different preferences, more educated patients may also be more aware, eloquent and assertive when demanding additional multidisciplinary palliative care.

Movements between care settings at the very end of life should be in line with the patient's medical condition, treatment goal, and the patient's wishes. Frequent and certainly unnecessary movements between care settings at the very end 
Table 2. Frequency of End-of-Life Care Use in the Last Three Months of Life According to Educational Level Among Patients Dying not Suddenly, Belgium, 2005-2007

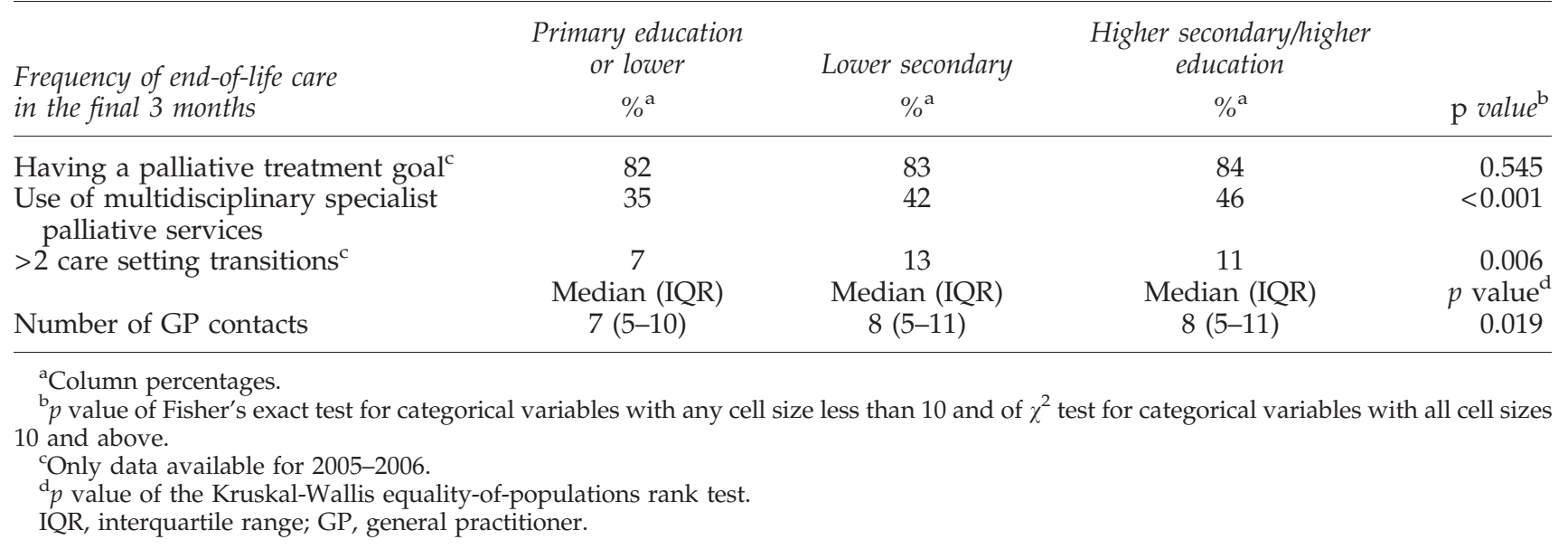

of life may be burdensome to the patient, who also runs the risk of discontinuity of care. ${ }^{34}$ The fact that less educated people have fewer transitions than their more educated counterparts may be due to a difference in preference regarding place of care, or due to an incapacity to organize a desired transition. Although seemingly contradictory, the findings regarding multidisciplinary palliative care services use and care setting transitions could both be explained by the fact that better educated people may be more assertive when demanding additional care that cannot always be provided at home, which may result in having more care setting transitions. Another hypothesis is that not all patients have already a palliative treatment goal 3 months before death and that higher educated people could have a another pattern of care consumption in the phase preceding the palliative phase. Differentials in transitions could also be due to GP related factors, e.g., GPs may refer patients with a different educational level differently. As we corrected for place of residence, differential presence of nursing home patients (usually a lower educated group with less care setting transitions at the end of life ${ }^{24-27}$ ) cannot explain the findings. Further research into individual needs and preferences regarding place of care as well as into prerequisites of transitions at the very end of life is therefore warranted.

Within the general population, there is inconclusive evidence of differential volume of general practice utilization according to educational level or income. ${ }^{6,11,35}$ In the final months of life, despite the provided financial measures in order to ensure an egalitarian health policy regarding utilization of general practice and in contrast with other studies on differentials according to financial status, ${ }^{19}$ we found that less educated patients have significantly fewer encounters with their GP in that period, even after accounting for place of death. Possible explanations are the health literacy being too low for adequately seeking medical care in general practice, a potentially higher hospitalization rate among the less educated and higher GP care consumption in the pre-palliative phase among more educated patients.

Table 3. Multivariable Multilevel Analysis: Association Between Individual Educational Attainment and End-of-Life Care Use, Adjusted for Individual and Contextual Factors, Belgium, 2005-2007

\begin{tabular}{|c|c|c|c|c|}
\hline $\begin{array}{l}\text { End-of-life care in the final } \\
3 \text { months }\end{array}$ & $\begin{array}{l}\text { Primary education or } \\
\text { lower adjusted } O R^{\mathrm{a}}\end{array}$ & $\begin{array}{l}\text { Lower secondary } \\
\text { adjusted } O R^{\mathrm{a}} \\
\quad(95 \% \mathrm{CI})\end{array}$ & $\begin{array}{c}\text { Higher secondary/ higher education } \\
\text { adjusted OR } \\
(95 \% \text { CI })\end{array}$ & $\mathrm{p}$ value \\
\hline Having a palliative treatment goal ${ }^{\mathrm{b}}$ & 1 & $1.12(0.76-1.67)$ & $1.07(0.69-1.64)$ & 0.846 \\
\hline $\begin{array}{l}\text { Use of multidisciplinary specialist } \\
\text { palliative services }{ }^{c}\end{array}$ & 1 & $1.28(1.04-1.59)$ & $1.31(1.02-1.68)$ & 0.028 \\
\hline$\geq 2$ care setting transitions ${ }^{\mathrm{b}}$ & $\begin{array}{l}1 \\
\text { regression } \\
\text { coefficient }\end{array}$ & $\begin{array}{l}1.68(1.13-2.48) \\
\text { regression coefficient }\end{array}$ & $\begin{array}{l}1.51(0.93-2.48) \\
\text { regression coefficient }\end{array}$ & $\begin{array}{c}0.033 \\
\text { p-value }\end{array}$ \\
\hline Number of GP contacts ${ }^{\mathrm{d}}$ & 0 & $\begin{array}{c}(95 \% \mathrm{CI}) \\
0.93(0.26-1.60)\end{array}$ & $\begin{array}{c}(95 \% \mathrm{CI}) \\
1.03(0.34-1.72)\end{array}$ & 0.002 \\
\hline
\end{tabular}

${ }^{a}$ Results from a marginal logistic regression model with GEE approach.

${ }^{\mathrm{b}}$ Adjusted for the independent variables mentioned in ${ }^{\mathrm{a}}$ and additionally for living alone and financial status.

'Adjusted for the patient's educational level, gender, age group, place of residence, cause of death and level of urbanization of the place of residence) and the GP's age group, gender, region, type of practice, size of the practice and trainee in the practice) and significant two-way interaction terms.

${ }^{\mathrm{d}}$ Adjusted for the patient's educational level, gender, age group, place of death, cause of death and level of urbanization of the place of residence) and the GP's age group, gender, region, type of practice, size of the practice and trainee in the practice) and significant two-way interaction terms.

$\mathrm{OR}$, odds ratio; $\mathrm{CI}$, confidence interval; GEE, generalized estimating equations; GP, general practioner. 
A major strength of collecting data via the GP is that Belgian GPs can provide useful and representative information on endof-life care in the Belgian population of people dying not suddenly. General practice is highly accessible and very frequently used in Belgium. ${ }^{36}$ Belgian GPs have a pivotal function in both general health care and multidisciplinary palliative home care, given their longstanding relationship with the patient and their close collaboration with palliative home care support teams. They receive and centralize the majority of the medical information on the encounters with other medical services. The representativeness of this sample regarding gender, age and cause of death was proven by comparing it with other published Belgian studies on end-of-life care. ${ }^{37,38}$ Since the study is based on this nationwide representative sample of the population of terminally ill patients across all health care settings and diagnoses and because several aspects of health care organization have been taken into account, the results are applicable nationwide. Because of the specific Belgian context, the results cannot be generalized internationally, but the methodology can easily be applied in the many countries that also have sentinel networks of GPs and where the GP has a comparable role in health care.

Several limitations of our study should be noted. Both the independent variable educational level and the outcome measures for end-of-life care were reported by the GP and not validated against external sources in this particular study. Regarding the study outcomes, GPs may indeed have underreported information concerning care at other settings than the home situation, because this information may not have been known to them and there may be a certain degree of recall bias due to the retrospective design. The educational level may also not been be known by the GP, as this type of information may be considered out of the scope of his activities. Future research into the validity of information on the socioeconomic status of the patient reported by the GP is thus needed. However, the vast majority of the Belgian population has frequent contacts with a regular GP, including a high percentage of home visits. ${ }^{36}$ Given his longstanding and close relationship with the patient and his family, the GP is in a good position of obtaining valid information on the social situation and sociodemographic background of his patients, especially in this study population of mostly elderly and chronically ill patients. Moreover, past registrations and other outcomes of this registration of end-of-life care demonstrated good external validity when comparing the results to data from external resources. ${ }^{39-41}$ Therefore, we consider the GP a reliable information provider, which justifies the use of these data.

Another related weakness of the analysis is that data on educational level was missing in $10 \%$ of the cases. Although the multiple imputations analysis suggests that a complete case analysis is justified, this analysis is inefficient and possibly biased. Furthermore, the fact that the model leaves a lot of variance unexplained can be due to the fact that many determinants of health care use were not accounted for. An important determinant is individual need, which in this study was only substituted by its proxy measure "main diagnosis." A closely related determinant, the individual preference of the patients regarding end-of-life care, was not measured here and should be further explored in future research.

In conclusion, significant differences were found according to the patient's level of educational achievement. They call for empowerment of less educated terminally ill people regarding specific aspects of palliative and general end-oflife care use.

\section{Acknowledgments}

The authors would like to thank the participating GPs for providing the data and Rita De Boodt of the Flemish Ministry of Welfare, Public Health, and Family for coding the cause of death.

The study protocol and anonymity procedures were approved by the ethical review board of the University Hospital of the Vrije Universiteit Brussel.

This study is part of the Monitoring Quality of End-of-Life Care (MELC) Study, a collaboration between the Vrije Universiteit Brussel, Ghent University, Antwerp University, the Scientific Institute of Public Health in Belgium, and VU University Medical Center Amsterdam in the Netherlands. Scientific director of the MELC study is Prof. dr. Luc Deliens of the Vrije Universiteit Brussel. This study is supported by a grant from the Institute for the Promotion of Innovation by Science and Technology in Flanders (SBO IWT nr. 050158). The Belgian Sentinel Network of GPs is funded by the authorities of the Flemish and French Community of Belgium.

L.v.d.B., V.v.C., and L.D. were involved in the conception and design of the study. K.M., L.v.d.B., and N.B. carried out data cleaning. Statistical analyses were carried out by N.B. and critically revised by all authors. The manuscript was drafted by N.B. with critical input from all other authors. All authors read, revised and approved the final manuscript.

\section{Author Disclosure Statement}

No competing financial interests exist.

\section{References}

1. Van Doorslaer E, Masseria C, Koolman X: Inequalities in access to medical care by income in developed countries. CMAJ 2006;174:177-183.

2. Hurst JW: Performance measurement and improvement in OECD health systems: overview of issues and challenges. In: Smith P (ed): Measuring Up: Improving Health System Performance in OECD Countries. Paris: OECD, 2002, pp. 35-54.

3. European Union: Charter of fundamental rights of the European Union. Official Journal of the European Communities 2000;C364.

4. Wagstaff A, Van Doorslaer E, Paci P: On the measurement of horizontal inequity in the delivery of health care. J Health Econ 1991;10:169-205.

5. Ratzan SC, Parker RM: Introduction. In: Selden CR, Zorn M, Ratzan SC, Parker RM (eds): National Library of Medicine Current Bibliographies in Medicine: Health Literacy. NLM Pub. No. CBM 2000-1. Bethesda, MD: National Institutes of Health, U.S. Department of Health and Human Services, 2000.

6. Baker DW, Parker RM, Williams MV, Clark WS, Nurss J: The relationship of patient reading ability to self-reported health and use of health services. Am J Public Health 1997;87:1027-1030.

7. Volandes AE, Paasche-Orlow MK: Health literacy, health inequality and a just healthcare system. Am J Bioeth 2007; 7:5-10.

8. Paasche-Orlow MK, Parker RM, Gazmararian JA, NielsenBohlman LT, Rudd RR: The prevalence of limited health literacy. J Gen Intern Med 2005;20:175-184. 
9. Sentell TL, Halpin HA: Importance of adult literacy in understanding health disparities. J Gen Intern Med 2006;21: 862-866.

10. Bennett IM, Chen J, Soroui JS, White S: The contribution of health literacy to disparities in self-rated health status and preventive health behaviors in older adults. Ann Fam Med 2009;7:204-211.

11. Glazier RH, Agha MM, Moineddin R, Sibley LM: Universal health insurance and equity in primary care and specialist office visits: A population-based study. Ann Fam Med 2009;7:396-405.

12. Addington-Hall J, Altmann D, McCarthy M: Which terminally ill cancer patients receive hospice in-patient care? Soc Sci Med 1998;46:1011-1016.

13. Beccaro M, Costantini M, Merlo DF: Inequity in the provision of and access to palliative care for cancer patients. Results from the Italian survey of the dying of cancer (ISDOC). BMC Public Health 2007;7:66.

14. Costantini M, Camoirano E, Madeddu L, Bruzzi P, Verganelli E, Henriquet F: Palliative home care and place of death among cancer patients: A population-based study. Palliat Med 1993;7:323-331.

15. Crawley LM: Racial, cultural, and ethnic factors influencing end-of-life care. J Palliat Med 2005;8(Suppl 1):S58-S69.

16. duPreez AE, Smith MA, Liou JI, Frytak JR, Finch MD, Cleary JF, Kind AJ: predictors of hospice utilization among acute stroke patients who died within thirty days. J Palliat Med 2008;11:1249-1257.

17. Grande GE, Farquhar MC, Barclay SI, Todd CJ: The influence of patient and carer age in access to palliative care services. Age Ageing 2006;35:267-273.

18. Gray JD, Forster DP: Factors associated with utilization of specialist palliative care services: A population based study. J Public Health Med 1997;19:464-469.

19. Hanratty B, Jacoby A, Whitehead M: Socioeconomic differences in service use, payment and receipt of illness-related benefits in the last year of life: Findings from the British Household Panel Survey. Palliat Med 2008;22:248-255.

20. Kessler D, Peters TJ, Lee L, Parr S: Social class and access to specialist palliative care services. Palliat Med 2005;19:105-110.

21. Belgisch Staatsblad 26 oktober 2002 [Belgian official collection of the laws Octobre 26 2002]. Wet betreffende palliatieve zorg 14 juni 2002 [Law concerning palliative care Belgium June 14, 2002] [in Dutch]. Number Bill 002022868, Brussels, Belgium. Belgian Law, 2002.

22. Belgisch Staatsblad 26 september 2002 [Belgian official collection of the laws September 26 2002]. Wet betreffende de rechten van de patiënt 22 augustus 2002 [Law concerning Patients' Rights August 22, 2002] [in Dutch]. Number Bill 2002009590, Brussels, Belgium. Belgian Law, 2002.

23. Broeckaert B, Janssens R: Palliative care and euthanasia: Belgian and Dutch perspectives. Ethical Perspect 2002;9:156-175.

24. Van den Block L, Deschepper R, Bilsen J, Van Casteren V, Deliens L:. Transitions between care settings at the end of life in belgium. JAMA 2007;298:1638-1639.

25. Van den Block L, Van Casteren V, Deschepper R, Bossuyt N, Drieskens K, Bauwens S, Bilsen J, Deliens L: Nationwide monitoring of end-of-life care via the Sentinel Network of General Practitioners in Belgium: The research protocol of the SENTI-MELC study. BMC Palliat Care 2007;6:6.

26. Van den Block L, Deschepper R, Bossuyt N, Drieskens K, Bauwens S, Van Casteren V, Deliens L: Care for patients in the last months of life: The Belgian Sentinel Network Monitoring End-of-Life Care study. Arch Intern Med 2008;168:1747-1754.

27. Van den Block L, Deschepper R, Bilsen J, Bossuyt N, Van Casteren V, Deliens L: Euthanasia and other end of life deci- sions and care provided in final three months of life: nationwide retrospective study in Belgium. BMJ 2009;339:b2772.

28. Boffin N, Bossuyt N, Van Casteren V: Caractéristiques des Médecins Vigies et de leur pratique. Situation en 2007 et comparaison avec les années précédentes. [in French]. Bruxelles: ISP-WIV; 2009. Report No. D/2009/2505/17, IPH/EPI REPORTS No 2009-016.

29. Griffin T, Peters TJ, Sharp D, Salisbury C, Purdy S: Validation of an improved area-based method of calculating general practice-level deprivation. J Clin Epidemiol 2010;63:746-751.

30. Andersen RM: National health surveys and the behavioral model of health services use. Med Care 2008;46:647-653.

31. Covinsky KE, Landefeld CS, Teno J, Connors AF, Jr., Dawson N, Youngner S, Desbiens N, Lynn J, Fulkerson W, Reding D, Oye R, Phillips RS: Is economic hardship on the families of the seriously ill associated with patient and surrogate care preferences? SUPPORT Investigators. Arch Intern Med 1996;156:1737-1741.

32. Volandes AE, Paasche-Orlow M, Gillick MR, Cook EF, Shaykevich S, Abbo ED, Lehmann L: Health literacy not race predicts end-of-life care preferences. J Palliat Med 2008;11:754-762.

33. Burge FI, Lawson BJ, Johnston GM, Grunfeld E: A population-based study of age inequalities in access to palliative care among cancer patients. Med Care 2008;46:1203-1211.

34. Coleman EA, Berenson RA: Lost in transition: Challenges and opportunities for improving the quality of transitional care. Ann Intern Med 2004;141:533-536.

35. Van der Heyden JH, Demarest S, Tafforeau J, Van Oyen H: Socio-economic differences in the utilisation of health services in Belgium. Health Policy 2003;65:153-165.

36. Bayingana K, Demarest S, Drieskens S, Miermans P, Tafforeau J, Van Der Heyden J, et al: Health Interview Survey, Belgium 2004. Scientific Institute of Public Health Belgium, Department of Epidemiology; 2007. Report No. D/2006/ 2505/4, IPH/EPI REPORTS N²006-035.

37. van der Heide A, Deliens L, Faisst K, Nilstun T, Norup M, Paci E, van der Wal G, van der Maas PJ; EURELD consortium: End-of-life decision-making in six European countries: descriptive study. Lancet 2003;362:345-350.

38. Van den Block L, Bossuyt N, Van Casteren V, Deliens L: [Le lit de mort en Belgique]. Bruxelles: Academic \& Scientific Publishers, 2009.

39. Devroey D, Van Casteren V, Buntinx F: Registration of stroke through the Belgian sentinel network and factors influencing stroke mortality. Cerebrovasc Dis 2003;16:272-279.

40. Gielen B, Remacle A, Mertens R: Patterns of health care use and expenditure during the last 6 months of life in Belgium: Differences between age categories in cancer and non-cancer patients. Health Policy 2010;97:53-61.

41. Cohen J, Bilsen J, Hooft P, Deboosere P, van der Wal G, Deliens L: Dying at home or in an institution using death certificates to explore the factors associated with place of death. Health Policy 2006;78:319-329.

Address correspondence to: Nathalie Bossuyt, M.D. Health Services Research Programme Operational Directorate Public Health \& Surveillance Scientific Institute of Public Health J. Wytsmanstraat 14 1050 Brussel Belgium

E-mail: nathalie.bossuyt@wiv-isp.be 